\title{
Report
}

\section{Comparing phreatic evaporation at zero water table depth with water surface evaporation}

\author{
HU Shunjun $^{1 *}$, GAN Yongde ${ }^{1,2}$, CHEN Yongbao ${ }^{1,3}$ \\ ${ }^{1}$ State Key Laboratory of Desert and Oasis Ecology, Xinjiang Institute of Ecology and Geography, Chinese Academy of \\ Sciences, Urumqi 830011, China; \\ ${ }^{2}$ State Key Laboratory of Simulation and Regulation of Water Cycle in River Basin, China Institute of Water Resources and \\ Hydropower Research, Beijing 100038, China; \\ ${ }^{3}$ Central South Institute of Metallurgical Geology, Yichang 443003, China
}

\begin{abstract}
Salt-affected soils are mostly found in irrigated areas within arid and semi-arid regions where the groundwater table is shallow. Soils of this type have become an increasingly severe problem because they threaten both the environment and the sustainable development of irrigated agriculture. A tool to estimate phreatic evaporation is therefore urgently required to minimize the salinization potential of salt-affected areas. In this context, phreatic evaporation at zero water table depth $\left(E_{0}\right)$ is a key parameter for establishing a model for calculating phreatic evaporation. The aim of this study was to explore the law of phreatic evaporation and to develop structurally rational empirical models for calculating phreatic evaporation, based on $E_{0}$ data of six types of soil (i.e., gravel, fine sand, sandy loam, light loam, medium loam, and heavy loam) observed using the non-weighing lysimeter and water surface evaporation $\left(E_{601}\right)$ data observed using a E601 evaporator of same evaporation area with a lysimeter-tube at the groundwater balance station of the Weigan River Management Office in Xinjiang Uygur Autonomous Region, China, during the non-freezing period (April to October) between 1990 and 1994. The relationship between $E_{0}$ and $E_{601}$ was analyzed, the relationship between the ratio of $E_{0}$ to $E_{601}$ and the mechanical compositions of different soils was presented, and the factors influencing $E_{0}$ were discussed. The results of this study reveal that $E_{0}$ is not equal to $E_{601}$. In fact, only values of the former for fine sand are close to those of the latter. Data also show that $E_{0}$ values are related to soil texture as well as to potential atmospheric evaporation, the ratio of $E_{0}$ to $E_{601}$ and the silt-clay particle content (grain diameter less than $0.02 \mathrm{~mm}$ ) is negatively exponentially correlated, and that soil thermal capacity plays a key role in phreatic evaporation at $E_{0}$. The results of this analysis therefore imply that the treatment of zero phreatic depth is an essential requirement when constructing groundwater balance stations to study the law of phreatic evaporation.
\end{abstract}

Keywords: phreatic evaporation; water table depth; water surface evaporation; soil texture; soil thermal capacity

Citation: HU Shunjun, GAN Yongde, CHEN Yongbao. 2018. Comparing phreatic evaporation at zero water table depth with water surface evaporation. Journal of Arid Land, 10(6): 968-976. https://doi.org/10.1007/s40333-018-0108-9

\section{Introduction}

Phreatic evaporation from bare soil is a process that transfers water from phreatic zone to unsaturated zone before it passes into the air via soil evaporation. Understanding this process is of

\footnotetext{
*Corresponding author: HU Shunjun (E-mail: hushunjun@ms.xjb.ac.cn)

Received 2017-12-27; revised 2018-03-29; accepted 2018-05-14

C Xinjiang Institute of Ecology and Geography, Chinese Academy of Sciences, Science Press and Springer-Verlag GmbH Germany, part of Springer Nature 2018
} 
great importance to a range of research fields, including hydrology, hydrogeology, soil physics, and agriculture, especially in the context of evaluating water resource and calculating farmland drainage (Jin, 1982; Qu et al., 1983; Zhang, 1986, 1996, 2013; Huo and Wang, 1988; Lei et al., 1988; Shen, 1992; Wang, 1993; Wang et al., 1994; Zhang and Shen, 1998; Ma et al., 2006; Su and Tao, 2009). In arid and semi-arid regions where areas with a shallow groundwater table, this process is a particular issue because considerable amounts of water are lost to the atmosphere and salts are accumulated within upper parts of the soil profile. In places where the groundwater table is shallow, evaporation can also lead to increasingly severe soil salinization problems which result in a surface salt crust that hampers agricultural activities (Zarei et al., 2002, 2009); such crusts also threaten the environment and sustainable agricultural development in these regions (Williams, 1987) and are therefore critical factors affecting the stability of oasis agro-ecosystems. Soil secondary salinization is particularly serious within the Xinjiang region of northwestern China because of the evaporation of groundwater with less rainfall, a larger evaporation rate overall, and a shallow water table (Shi et al., 2013). At the same time, however, direct evaporation measurements over large scales are problematic, costly, time consuming, and often impractical (Zarei et al., 2010). It is therefore essential to establish a tool to estimate phreatic evaporation (capillary rise) to minimize the salinization potential within salt-affected areas. In this context, Averianov (1956) proposed an empirical equation to estimate phreatic evaporation (Eq. 1).

$$
E_{g}=E_{0}\left(1-\frac{H}{H_{\max }}\right)^{n},
$$

where $E_{\mathrm{g}}$ denotes phreatic evaporation intensity $(\mathrm{mm} / \mathrm{d})$ when the water table depth $(\mathrm{m})$ is $H$ (i.e., from the ground surface to the groundwater table); $E_{0}$ is the phreatic evaporation intensity $(\mathrm{mm} / \mathrm{d})$ when the water table depth is zero (a value which generally approximates surface water evaporation); $H_{\max }$ is the critical water table depth (m) at which evaporation ceases; and $n$ is the phreatic evaporation index.

Even though the relationship between $E_{\mathrm{g}}$ and $H$ is limited in expression, it has nevertheless been widely applied because it is a simple expression and requires fewer parameters (Zhang, 1986; Zammouri, 2001; Yang et al., 2011; Chen et al., 2013). At the same time, although the intensity of phreatic evaporation when the water table reaches the ground surface is an important parameter within the Averianov equation, limited research has been carried out regarding $E_{\mathrm{g}}$ when $H$ is zero. There are currently four main views regarding the relationship between phreatic evaporation and water table depth. The first view is that the phreatic evaporation at zero water table depth $\left(E_{0}\right)$ is equal to, or approximate to, water surface evaporation $\left(E_{601}\right)$ (Huo and Wang, 1988; Tang et al., 1989; Zhang, 1996; Guan, 2010; Xu, 2011; Shen and Huang, 2015). The second view is that phreatic evaporation at $E_{0}$ is more than $E_{601}$ (Shi and Liang, 1964; Liang, 1992; Tindall et al., 1999; Fang, 2009; Han et al., 2009; Rui, 2014), while the third argument holds that phreatic evaporation at $E_{0}$ is not equal to $E_{601}$ (Zheng, 1951; Don and William, 1958). The final view in this context suggests that phreatic evaporation is the same as $E_{601}$ when the depth of the water table is less than decoupling depth or that of the evapotranspiration (ET) surface (Wang, 1993; Cook and Rassam, 2002; Shah et al., 2007; Ridolfi et al., 2008; Johnson et al., 2010). In an earlier study, Saxena et al. (1971) noted that water is lost readily from most soils at rates comparable to those from a free water surface when the water table is shallower than $60 \mathrm{~cm}$, while Hillel (1998) considered $E_{0}$ to be equivalent to potential evaporation. In a later study carried out in Tunisia, Zammouri (2001) noted that the Averianov equation provides more accurate estimates of $E_{\mathrm{g}}$ than either the Gardner or MODFLOW approaches, while Blight (2002) concluded that more evaporation may occur from the bare soil surface than from the water surface. In a series of studies carried out within the Tarim River Basin, Yu (1993), Mao et al. (1998), Shang et al. (1999), and $\mathrm{Hu}$ et al. (2009) established a series of empirical equations for estimating $E_{\mathrm{g}}$ based on experimental data collected at the Qongkol, Shache, and Aksu water balance experimental stations in South Xinjiang, but in the absence of $E_{0}$ measurements. Additional information regarding phreatic evaporation intensity when the water table depth is zero should therefore be 
obtained to enable further studies regarding whether, or not, the phreatic evaporation at $E_{0}$ approximates $E_{601}$.

The objectives of this study are to: (1) identify whether phreatic evaporation for different soil textures is equal to $E_{601}$ (as measured by the E601 evaporator) when water table depth is zero; (2) analyze the relationships among phreatic evaporation at $E_{0}, E_{601}$, and the mechanical composition of different soils; and (3) provide a parameter to establish a calculation model for phreatic evaporation.

\section{Materials and methods}

\subsection{Study site}

The experiments described in this study were conducted using a non-weighing lysimeter (Fig. 1) at the groundwater balance station $\left(40^{\circ} 30^{\prime} \mathrm{N}, 82^{\circ} 33^{\prime} \mathrm{E} ; 1013 \mathrm{~m}\right.$ a.s.l.) operated by the Weigan River Management Office in Xinjiang Uygur Autonomous Region, China. The annual mean temperature is $10.7^{\circ} \mathrm{C}$, mean annual precipitation is $53.2 \mathrm{~mm}$, mean annual water surface evaporation is $2400 \mathrm{~mm}$ measured by an EФ20 evaporator, and annual frost-free days are $216 \mathrm{~d}$. The maximum frozen soil depth is $80 \mathrm{~cm}$, and there are 2900 annual hours of sunshine. The Weigan River Management Office experimental station encompasses $120 \mathrm{hm}^{2}$ where the soil mostly consists of a grey sandy loam and a yellow mild clay; these clay layers occur $2 \mathrm{~m}$ below the land surface within the profile.

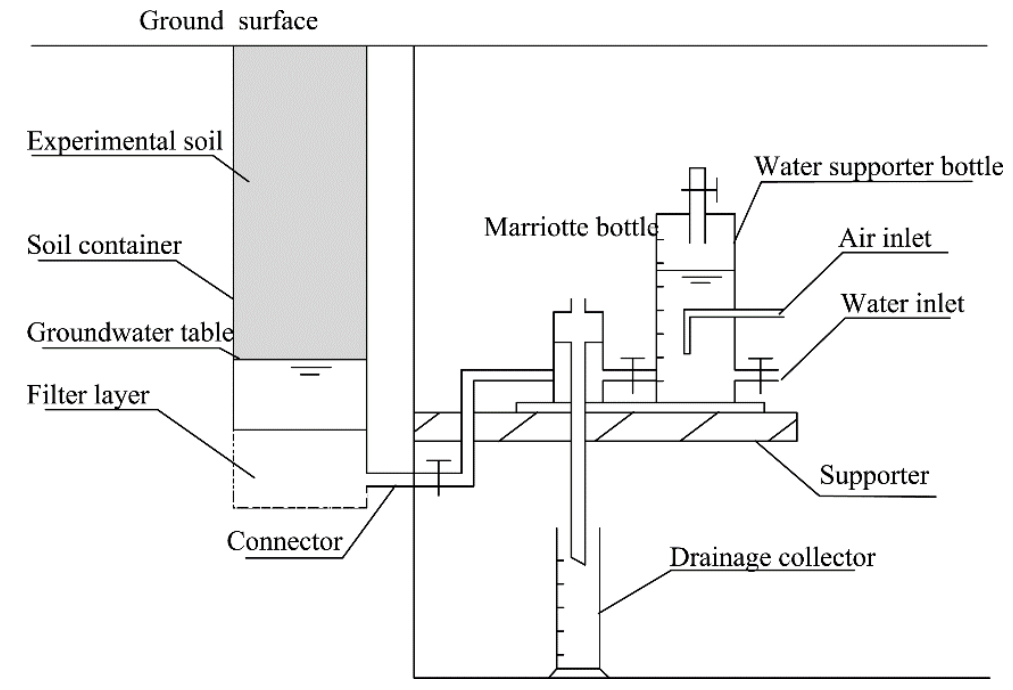

Fig. 1 Schematic illustration of the non-weighing lysimeter used in this study

\subsection{Experimental method}

To accurately encapsulate the range of soil textures seen within the Weigan River irrigation district, we filled a series of 54 lysimeters (cross-sectional area, $0.3 \mathrm{~m}^{2}$ ) with six types of soil (gravel, fine sand, sandy loam, light loam, medium loam, and heavy loam) at nine water table depths $(0.00,0.25,0.50,0.75,1.00,1.50,2.50,3.50$ and $4.50 \mathrm{~m})$ to observe phreatic evaporation (Fig. 2). The mechanical compositions of these six soil types are summarized in Table 1 (Lai et al., 2003). The lysimeters used for these experiments comprise a phreatic evaporation measuring cylinder, a Marriotte bottle, a drainage collector, and a connector (Fig. 1). Cylinders used to control water table depths less than $1.00 \mathrm{~m}$ were installed on both sides of the observation gallery, while those used to control water table depths more than $1.00 \mathrm{~m}$ were installed around the underground observation room (Fig. 2). A Marriotte bottle system was connected to the soil column in each case to control and record the internal water table and to measure the amount of water supplied to the soil column (Fig. 1). Gravity drainage was recorded by the collector, while 
the water supplied to each lysimeter from the Marriotte bottle was measured three times a day at 08:00, 14:00, and 20:00 (LST). Meteorological data were measured at a standard weather station within the experimental area; variables included air and ground temperature, humidity, hours of sunshine, wind speed at $2 \mathrm{~m}$ above the ground, rainfall, vapor pressure, and $E_{601}$.

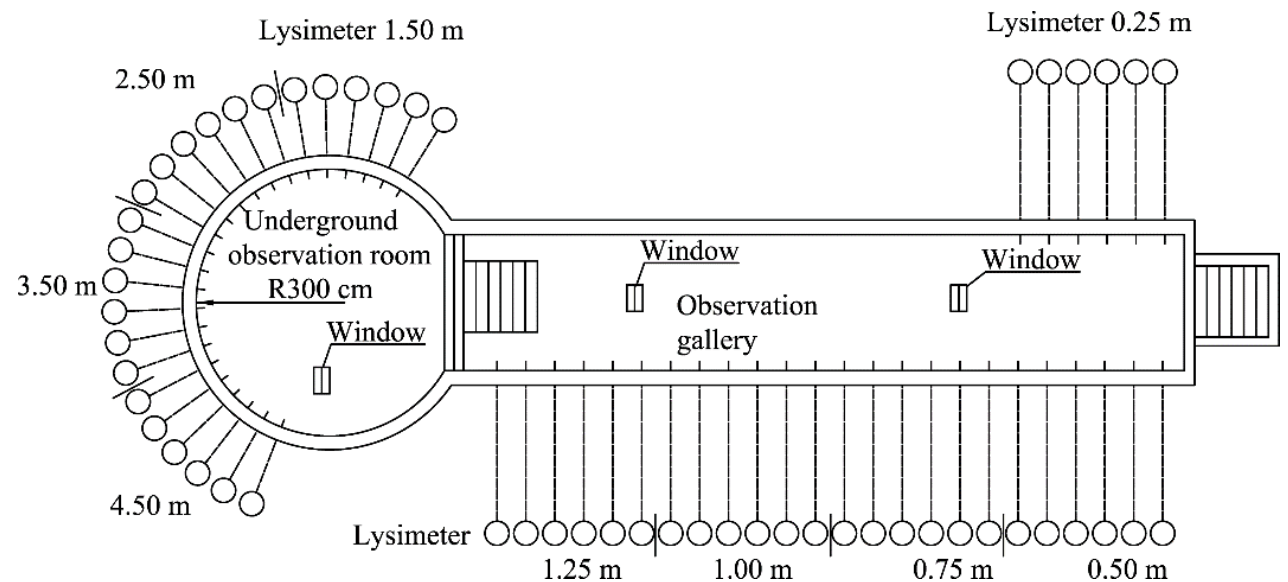

Fig. 2 Schematic illustration of the Weigan River groundwater evaporation station

Table 1 Soil mechanical composition

\begin{tabular}{lccr}
\hline \multirow{2}{*}{ Soil texture } & \multicolumn{3}{c}{ Weight percentage of soil particle content (\%) } \\
\cline { 2 - 4 } & $<0.02 \mathrm{~mm}$ & $0.02-0.25 \mathrm{~mm}$ & $>0.25 \mathrm{~mm}$ \\
\hline Gravel & 0.00 & 0.00 & 100.00 \\
Fine sand & 6.48 & 37.07 & 56.45 \\
Sandy loam & 32.36 & 67.11 & 0.53 \\
Light loam & 40.28 & 54.48 & 5.24 \\
Medium loam & 41.79 & 54.44 & 3.77 \\
Heavy loam & 54.95 & 44.22 & 0.83 \\
\hline
\end{tabular}

\section{Results}

\subsection{Relationship between phreatic evaporation at zero water table depth $\left(E_{0}\right)$ and water surface evaporation $\left(E_{601}\right)$}

Data reveal the relationship between the phreatic evaporation intensity of the six soil types in the Weigan River irrigation district when water table depth is zero and $E_{601}$ (Fig. 3). Results reveal that the phreatic evaporation intensity of all six soil types at $E_{0}$ within this region is linearly related to $E_{601}$ (Fig. 3). This relationship is extremely significant as the correlation coefficient is greater than 0.86 and can be expressed as Equation 2 .

$$
E_{0}=\beta \times E_{601},
$$

where $\beta$ denotes the slope of the correlation equation between phreatic evaporation intensity when water table depth is zero and $E_{601}(\mathrm{~mm} / \mathrm{d})$, while $E_{601}$ denotes the water surface evaporation measured by the E601 evaporator.

Thus, if $\beta$ equals 1 , then $E_{0}$ is equal to $E_{601}$. Results further reveal the slope of the correlation equation between phreatic evaporation of the six soil types when water table depth is zero and $E_{601}$ within the Weigan River irrigation district (Table 2); as these data show that the $\beta$ value corresponding to the six soil types does not equal one, replacing $E_{0}$ with $E_{601}$ and establishing an empirical equation to calculate phreatic evaporation corresponding to different water table depths will generate a larger error. 
Table 2 Correlation equation slopes between $E_{0}$ and $E_{601}$

\begin{tabular}{lccccc}
\hline Soil texture & Slope $\beta$ & $R^{2}$ & $R$ & $R_{0.01}$ & Significance level \\
\hline Gravel & 1.2778 & 0.9257 & 0.9621 & 0.2944 & Extremely significant \\
Fine sand & 1.1026 & 0.8866 & 0.9416 & 0.3204 & Extremely significant \\
Sandy loam & 0.7690 & 0.7538 & 0.8682 & 0.3395 & Extremely significant \\
Light loam & 0.6606 & 0.7397 & 0.8601 & 0.2798 & Extremely significant \\
Medium loam & 0.5586 & 0.7600 & 0.8718 & 0.3089 & Extremely significant \\
Heavy loam & 0.4999 & 0.7669 & 0.8757 & 0.3612 & Extremely significant \\
\hline
\end{tabular}

Note: $E_{0}$, phreatic evaporation at zero water table depth; $E_{601}$, water surface evaporation; $\beta$, slope; $R^{2}$, determination coefficient; $R$, correlation coefficient; $R_{0.01}$, critical correlation coefficient.
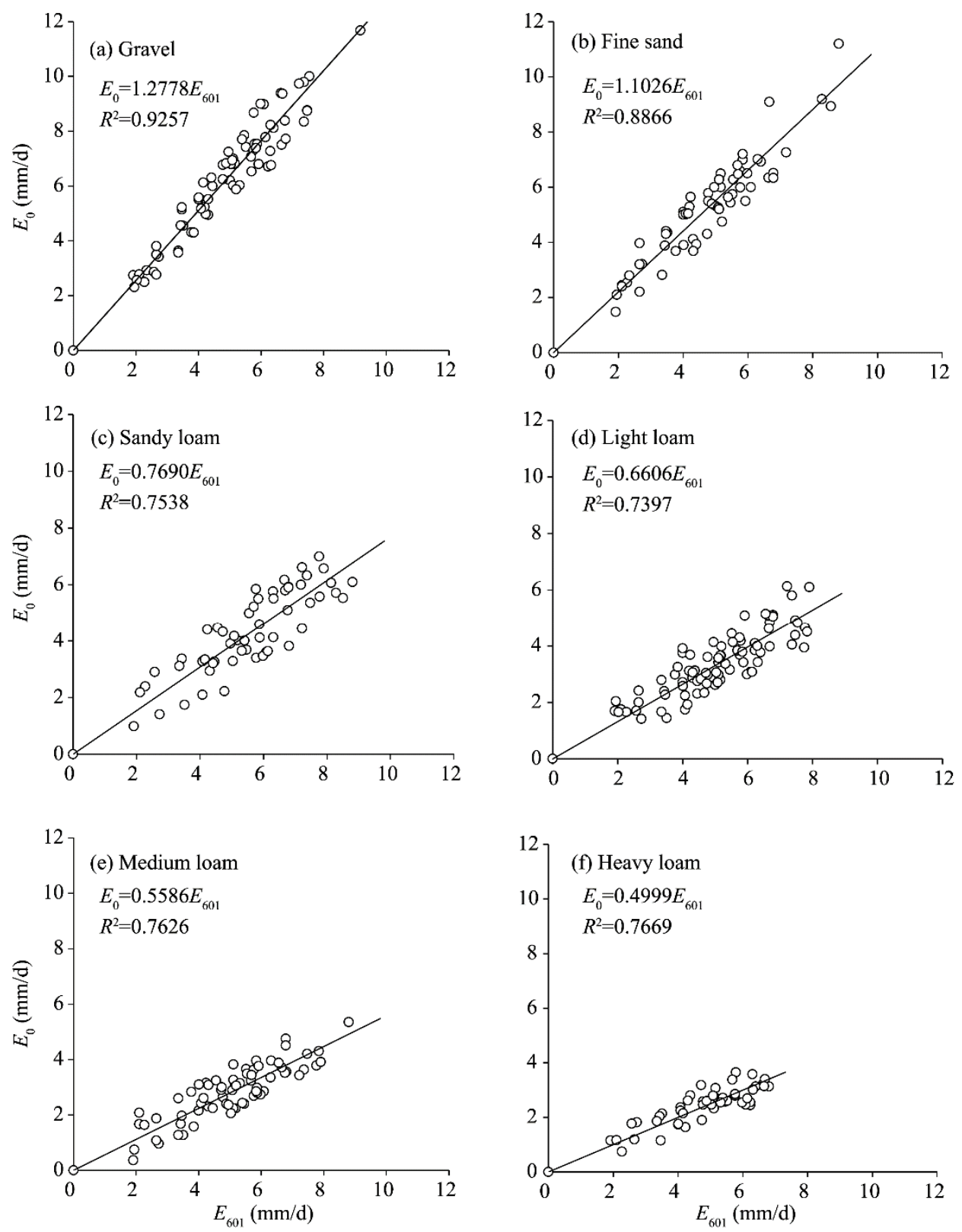

Fig. 3 Relationships between phreatic evaporation at zero water table depth $\left(E_{0}\right)$ and water surface evaporation $\left(E_{601}\right)$ for six soil types 


\subsection{Relationships of $E_{0}, E_{601}$ and soil mechanical composition}

The data presented in Figure 4 illustrate the relationship among $E_{0}, E_{601}$, and the percentage of silt-clay particle $(<0.02 \mathrm{~mm})$ content $(C)$ of a soil type. The ordinate in this figure is the ratio between $E_{0}$ and $E_{601}$, the slope of the correlation equation between phreatic evaporation intensity when water table depth is zero and $E_{601}$. This was obtained by regressing Equation 2 (Table 2), and can be fitted with an exponential function (Eq. 3).

$$
\frac{E_{0}}{E_{601}}=1.2622 \mathrm{e}^{-0.0170 C} \text {. }
$$

In this case, the regression is extremely significant.

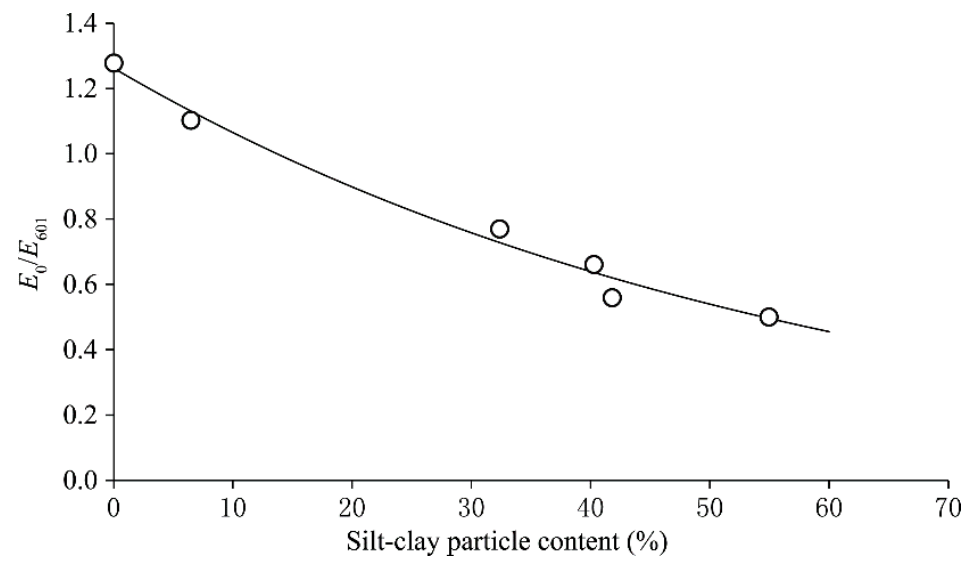

Fig. 4 Relationship between $E_{0} / E_{601}$ and silt-clay particle content

\section{Discussion and conclusions}

The Averianov equation shows that phreatic evaporation at $E_{0}$ is equal to $E_{601}$. The experimental results presented in this study reveal that $E_{0}$ is greater than $E_{601}$ in the case of gravel, but less than $E_{601}$ in the case of loam, only approximate $E_{601}$ in the case of fine sand within the Weigan River irrigated area. This analysis therefore suggests that additional research on phreatic evaporation at a water table depth of zero would be worthwhile.

Phreatic evaporation at $E_{0}$ refers to the evaporative process from a saturated soil surface (Jin, $1982)$ as well as directly from phreatic water. As an oasis effect is also present when observing phreatic evaporation and $E_{601}$ at the same time, the evaporation area within phreatic evaporation measuring cylinders was held the same as in the E601 evaporator. Because environmental conditions were also the same throughout experiments, Equation 2 shows that applying the ratio between $E_{0}$ and $E_{601}$ weakens the oasis effect in this study.

The experimental results presented here also show that phreatic evaporation at $E_{0}$ decreases in concert with soil particle size. This corroborates the earlier findings of Don and Willian (1958), but conflicts with some other previous researches. It is generally recognized that when soils are very wet, the evaporation of water is governed by external atmospheric conditions rather than by their inherent properties; evaporation rate is therefore equivalent to potential rate, referred to as "potential evaporation", i.e., $E_{601}$ ( Hanks and Ashcroft, 1984; Jury et al., 1991; Hanks, 1992; Hillel, 1998, 2004; Lal and Shukla, 2004). Phreatic evaporation at $E_{0}$ is not only related to potential atmospheric evaporation, but also is influenced by evaporation surface roughness, soil heat capacity, soil thermal conductivity, soil color, and soil surface albedo.

The data assembled in this analysis show that the particle sizes of the six soil types decrease in concert with evaporative surface roughness. Indeed, as an aerodynamically rough surface increases the turbulent mixing of air, $E_{0}$ for gravel is greater than $E_{601}$. As a rough irregular surface also has a greater evaporation area (Tang et al., 1992; Wang, 2016), phreatic evaporation at $E_{0}$ should increase (Wu and Zhang, 1986; Liang, 1992; Tindall et al., 1999; Cui, 2006; Lu and $\mathrm{Pu}, 2006$; Fan et al., 2014; Shen and Huang, 2015). This theoretical result is inconsistent with the 
experimental results of this study.

Soil thermal capacity and thermal conductivity are closely related to mechanical composition. Thus, if soil thermal capacity is large, the temperature rise will be small when the surface is heated, water molecules will move slowly, and little water evaporation will occur. Previous research has also shown that soil heat capacity increases in concert with water content (De Vries, 1963; Jury et al., 1991; Moldup et al., 2000; Wang, 2016). This means that as soil particle size decreases, saturated soil water content increases (Cosby et al., 1984) alongside thermal capacity while phreatic evaporation at $E_{0}$ should decrease (Hu and Hou, 1988; Fang, 2009; Rui, 2014). This theoretical result agrees reasonably well with the experimental results of this study.

The net radiation $\left(R_{\mathrm{n}}\right)$ received by a bare soil surface is partitioned into heating the soil and atmosphere, and evaporating water. Thus, under steady-state conditions (i.e., time-invariant and horizontally homogeneous), surface energy budget can be expressed as follows (Tindall et al., 1999):

$$
R_{n}=S+\mathrm{LE}+G
$$

where $S$ denotes sensible-heat flux $\left(\mathrm{W} / \mathrm{m}^{2}\right)$; LE denotes latent-heat flux $\left(\mathrm{W} / \mathrm{m}^{2}\right)$; and $G$ refers to soil heat flux $\left(\mathrm{W} / \mathrm{m}^{2}\right)$ (Tindall et al., 1999).

The heat flow equation can be written as follows (Hanks, 1992):

$$
G=-K_{\mathrm{q}} \frac{\Delta T}{\Delta z}=-K_{\mathrm{q}} \frac{\left(T_{0}-T_{1}\right)}{\Delta z},
$$

where $K_{\mathrm{q}}$ denotes soil thermal conductivity $\left(\mathrm{W} /\left(\mathrm{m} \cdot{ }^{\circ} \mathrm{C}\right)\right) ; T_{0}$ denotes soil surface temperature $\left({ }^{\circ} \mathrm{C}\right)$; and $T_{1}$ is the soil temperature at the soil depth of $\Delta z(\mathrm{~m})$.

This energy balance relationship predicts that when soil thermal conductivity is large, more heat will be conducted from the soil surface into deep soil, while latent heat will be lower and the amount of evaporated water will be small. This means that as soil particle size decreases, saturated water content increases (Cosby et al., 1984) and the thermal conductivity of a saturated soil will fall (Chung, 1987; Jury et al., 1991; Wang, 2016; Wang et al., 2016). Thus, in theory, phreatic evaporation at $E_{0}$ should increase, an outcome that is inconsistent with the experimental results of this study. We therefore conclude that soil thermal capacity exerts a significant influence on phreatic evaporation at $E_{0}$.

The potential phreatic evaporation refers to the removal of water from a fully saturated soil surface when the depth of the water table is less than the decoupling depth, the depth of ET surface, or the thickness of the capillary saturated zone. However, as upward water flow must be high enough to match the external rate, small variations in the position of the water table around zero will not markedly influence the evaporation rate so long as these changes remain less than the decoupling depth, the depth of ET surface, or the thickness of the capillary saturated zone.

When all soil particles are fully submerged as a result of controlling the water table depth, it is clear that measured phreatic evaporation will be equal to $E_{601}$. This phenomenon may explain why some researchers have mistakenly noted that phreatic evaporation at $E_{0}$ is equal to $E_{601}$.

Soil color affects surface albedo and the absorption of solar radiation by the soil (i.e., soil color influences soil evaporation by changing evaporation surface temperature). In other words, the darker the soil, the more the heat is absorbed by soil, the faster the soil surface temperature rises, the higher the evaporation surface temperature, and the greater the evaporation. Experimental data show that evaporation from a brown soil is $19 \%$ higher than that from a white soil, while evaporation from a black soil is $32 \%$ higher than that from a white one. Similarly, evaporation from a yellow soil will be 7\% higher than that from a white soil (Shi, 1959; Fan et al., 2014; Shen and Huang, 2015). The influence of soil color and albedo on phreatic evaporation at $E_{0}$ also require further study.

The results of this study lead to the suggestion that phreatic evaporation at $E_{0}$ should be taken into account when groundwater balance stations are constructed to study the phreatic evaporation.

\section{Acknowledgements}

This study was funded by the National Natural Science Foundation of China (41671032, U1303181), the Key Special Project of National Key Research and Development Program of China (2016YFC0501401), and the 
National Basic Research Program of China (2013CB429902).

\section{References}

Averianov S F. 1956. Seepage from irrigation canals and its influence on regime of ground water table. In: Kostiakov A N, Favorin N N, Averianov S F. Influence of Irrigation Systems on Regime of Ground Water. Moscow: Academic Press, 140151. (in Russian)

Blight G E. 2002. Measuring evaporation from soil surfaces for environmental and geotechnical purposes. Water SA, 28(4): 381-394.

Chen T F, Wang X S, Li H L, et al. 2013. Redistribution of groundwater evapotranspiration and water table around a well field in an unconfined aquifer: A simplified analytical model. Journal of Hydrology, 495: 162-174.

Chung S O, Horton R. 1987. Soil heat and water flow with a partial surface mulch. Water Resources Research, 23(12): 2175-2186.

Cook F J, Rassam D W. 2002. An analytical model for predicting water table dynamics during drainage and evaporation. Journal of Hydrology, 263(1-4): 105-113.

Cosby B J, Hornerger G M, Clapp R B, et al. 1984. A statistical exploration of the relationships of soil moisture characteristics to the physical properties of soils. Water Resources Research, 20(6): 682-690.

Cui M X. 2006. Agricultural Meteorology. Beijing: Higher Education Press, 64-65. (in Chinese)

De Vries D A. 1963. Thermal properties of soils. In: Van Wijk W R. Physics of Plant Environment. Amsterdam: North-Holland Publishing, 210-235.

Don J, William P G. 1958. Elements of Applied Hydrology. New York: Ronal Press, 150-151.

Fan S X, Dao Y F, Liu J. 2014. Principles of Hydrology. Beijing: China Water and Power Press, 91-94. (in Chinese)

Fang M H. 2009. Environmental Hydrology. Beijing: China Science and Technology Press, 15. (in Chinese)

Guan H. 2010. Hydrology. Beijing: Science Press, 26. (in Chinese)

Han B Z, Liu J Z, Fu J W. 2009. Concept of soil evaporation and its determining method. Heilongjiang Science and Technology of Water Conservancy, 37(2): 106. (in Chinese)

Hanks R J, Ashcroft G L. 1984. Applied Soil Physics: Soil Water and Temperature Applications. Beijing: China Water and Power Press, 104-106.

Hanks R J. 1992. Applied Soil Physics: Soil Water and Temperature Applications (2 ${ }^{\text {nd }}$ ed.). New York: Springer-Verlog New York, Inc., 87-88, 114.

Hillel D. 1998. Environmental Soil Physics. New York: Academic Press, 514-515.

Hillel D. 2004. Introduction to Environmental Soil Physics. New York: Academic Press, 343-344.

Hu F R, Hou Y G. 1988. Principles of Hydrology. Beijing: China Water and Power Press, 89. (in Chinese)

Hu S J, Tian C Y, Song Y D. 2009. Empirical models of calculating phreatic evaporation from bare soil in Tarim River Basin, Xinjiang. Environmental Earth Sciences, 59(3): 663-668.

Huo C R, Wang Y L. 1988. Groundwater Hydrology. Beijing: China Water and Power Press, 104. (in Chinese)

Jin G Y. 1982. Evaluation of Groundwater Resources in a Plain Area. Beijing: China Hydraulic Press, 41-47. (in Chinese)

Johnson E, Yáñez J, Ortiz C, et al. 2010. Evaporation from shallow groundwater in closed basins in the Chilean Altiplano. Hydrological Sciences Journal, 55(4): 624-635.

Jury W A, Gardner W R, Gardner W H. 1991. Soil Physics ( $5^{\text {th }}$ ed.). New York: John Wiley \& Sons, 178-184.

Lal R, Shukla M K. 2004. Principles of Soil Physics. New York: Marcel Dekker, 411.

Lei Z D, Yang S X, Xie S C. 1988. Soil-Water Dynamics. Beijing: Tsinghua University Press, 133-146. (in Chinese)

Liang X T. 1992. Principles of Hydrology. Beijing: China Water and Power Press, 99. (in Chinese)

Lu Z Q, Pu X G. 2006. Calculating model study of the soil evaporation in the Heilongjiang region. South to North Water Transfers and Water Science \& Technology, 4 (Suppl.): 39-41. (in Chinese)

Ma Y J, Shen B, Tumaerbay H. 2006. Spacing of drainage ditches in field under the influence of evaporation. Journal of Hydraulic Engineering, 37(10): 1264-1269. (in Chinese)

Mao X M, Li M, Shen Y L, et al. 1998. Analysis of the phreatic evaporation in Yarkant River Basin, Xinjiang. Arid Land Geography, 21(3): 44-50. (in Chinese)

Moldup P, Olesen T, Schjønning P, et al. 2000. Predicting the gas diffusion coefficient in undisturbed soil from soil water characteristics. Soil Science Society of America Journal, 64(1): 94-100.

Qu X Y, Zhang Y Y, Su J X, et al. 1983. Phreatic evaporation and calculation of non-stable flow drainage under depth index relations $n=3$. Journal of Hydraulic Engineering, (9): 48-53. (in Chinese) 
Ridolfi L, D'Odorico P, Laio F, et al. 2008. Coupled stochastic dynamics of water table and soil moisture in bare soil conditions. Water Resources Research, 44(1): 423-432.

Rui X F. 2014. Principles of Hydrology. Beijing: China Water and Power Press, 114-118. (in Chinese)

Saxena G S, Taylor G S, Prankling R E. 1971. Effect of environmental factors on evaporation rates from soils in the presence of a water table. Journal of the Indian Society of Soil Science, 19: 23-29.

Shah N, Nachabe M, Ross M. 2007. Extinction depth and evapotranspiration from ground water under selected land covers. Groundwater, 45(3): 329-338.

Shang S H, Mao X M, Lei Z D. et al. 1999. Inverse-logistic formula for calculation of phreatic evaporation coefficient. Irrigation and Drainage, 18(2): 18-21. (in Chinese)

Shen B, Huang H H. 2015. Principles of Hydrology. Beijing: China Water and Power Press, 66-69. (in Chinese)

Shen Z R. 1992. Water resources scientific experiment and research—atmospheric, surface, soil and ground water interactions. Beijing: China Science and Technology Press, 213-231. (in Chinese)

Shi C X. 1959. Land Hydrology. Beijing: Science Press, 215-217. (in Chinese)

Shi C X, Liang R J. 1964. Principles of Land Hydrology. Beijing: China Industry Press, 30-31. (in Chinese)

Shi W J, Xing X G, Zhang Z H, et al. 2013. Groundwater evaporation from saline soil under plastic mulch with different percentage of open area. Journal of Food Agriculture and Environment, 11(2): 1268-1271.

Shu L C, Tao Y Z. 2009. Groundwater Hydrology. Beijing: China Water and Power Press, 88-90. (in Chinese)

Tang D X, Liu Y R, Zhang W S, et al. 1992. Engineering Geology. Beijing: Geological Publishing House, 28. (in Chinese)

Tang H X, Su Y S, Zhang H P. 1989. Experimental research on phreatic evaporation and improvement of its empirical formula. Journal of Hydraulic Engineering, 10: 37-44. (in Chinese)

Tindall J A, Kunkel J R, Anderson D E. 1999. Unsaturated Zone Hydrology for Scientists and Engineers. New Jersey: Prentice Hall, Inc., 215, 230-231.

Wang C J. 1993. Calculation and Evaluation of Water Resources. Nanjing: Nanjing University Press, 147-148. (in Chinese)

Wang K. 2016. Soil and Crop Science ( $4^{\text {th }}$ ed.). Beijing: China Water and Power Press, 18. (in Chinese)

Wang Q J. 2016. Soil Physics and Crop Growth Model. Beijing: China Water and Power Press, 87-93. (in Chinese)

Wang W Y, Shen B, Li Z L. 1994. Drain-spacing calculation considering influence of evaporation. Journal of Irrigation and Drainage Engineering, 120(3): 563-572.

Williams W D .1987. Salinization of rivers and streams: an important environmental hazard. Ambio, 16(4): 180-185.

Wu H G, Zhang Z M. 1986. Meteorology. Beijing: China Water and Power Press, 159. (in Chinese)

Xu W C. 2011. Calculation and Management of Water Resources. Beijing: Science Press, 22-23, 96-97. (in Chinese)

Yang F, Zhang G X, Yin X R, et al. 2011. Study on capillary rise from shallow groundwater and critical water table depth of a saline-sodic soil in western Songnen plain of China. Environmental Earth Sciences, 64(8): 2119-2126.

Yu Q H. 1993. Study of the evaporation of phreatic water in the northeastern margin of Tarim Basin. Xinjiang Geology, 11(3): 246-254. (in Chinese)

Zammouri M. 2001. Case study of water table evaporation at Ichkeul Marshes (Tunisia). Journal of Irrigation and Drainage Engineering, 127(5): 265-271.

Zarei G, Homaee M, Liaghat A M. 2002. An analytical solution of nonsteady evaporation from bare soils with shallow ground water table. Developments in Water Science, 47(2): 113-120.

Zarei G, Homaee M, Liaghat A M. 2009. Modeling transient evaporation from descending shallow groundwater table based on Brooks-Corey retention function. Water Resources Management, 23(14): 2867-2876.

Zarei G, Homaee M, Liaghat A M, et al. 2010. A model for soil surface evaporation based on Campbell's retention curve. Journal of Hydrology, 380(3-4): 356-361.

Zhang C X. 1996. Analysis on relationship between water surface evaporation and phreatic evaporation when phreatic depth is zero for different soils. Water Resources Research, 17(2): 27-28. (in Chinese)

Zhang W Z. 1986. New drainage formulas considering delayed gravity response and evaporation from shallow water table. In: Smith K V H, Rycroft D W. Hydraulic Design in Water Resources Engineering: Land drainage. Berlin: Spring-Verlag Berlin Heidelberg, 35-47.

Zhang W Z. 1996. Groundwater and Soil Water Dynamics. Beijing: China Water and Power Press, 239-242. (in Chinese)

Zhang W Z, Shen R K. 1998. Groundwater and Groundwater Control. Beijing: China Water and Power Press, 102-122. (in Chinese)

Zhang W Z. 2013. Calculation of Unsteady Flow of Groundwater and Evaluation of Groundwater Resources. Wuhan: Wuhan University Press, 10-12. (in Chinese)

Zheng Z J. 1951. Hydrology. Shanghai: The Commercial Press, 79. (in Chinese) 